\title{
A Crazy Gamble: Xintai Electric in China Malicious Fabrication and Packaging Market Case
}

\author{
Wenjing Ma \\ Accounting Department, Management School, Jinan University, Guangzhou, China \\ Email: wendyma1221@163.com
}

How to cite this paper: Ma, W.J. (2018) A Crazy Gamble: Xintai Electric in China Malicious Fabrication and Packaging Market Case. American Journal of Industrial and Business Management, 8, 393-403. https://doi.org/10.4236/ajibm.2018.82025

Received: January 18, 2018

Accepted: February 24, 2018

Published: February 27, 2018

Copyright $\odot 2018$ by author and Scientific Research Publishing Inc. This work is licensed under the Creative Commons Attribution International License (CC BY 4.0).

http://creativecommons.org/licenses/by/4.0/

\section{cc) (i) Open Access}

\begin{abstract}
On June 1st, 2016, Xintai Electric Co., Ltd. released an announcement that China Securities Regulatory Commission (CSCR) had finished its investigation for the company's suspicion of fraudulent issuing and illegal information disclosure, according to the administrative penalty and market access prohibition notification from CSCR. Xintai became the first company to be delisted due to fraudulent issuing, which drew concerns from numerous investors and regulators. August 25th, 2017 was the last day Xintai occupied an A-share market. From listing to delisting, going through three and a half years, Xintai left the market with a serious warning that the first company to be forcibly delisted in growth enterprise market for fraudulent initial public offering (IPO) will never appear on the market again. The present article conducts research into the internal control structure of listed company, in view of Xintai's financial fraud case. After reviewing the case and analyzing Xintai's current inner control situation, the paper tries to figure out deep links between financial fraud and internal control, and then put forward some measures to improve internal control, from the perspectives of COSO risk management framework and corporate governance.
\end{abstract}

\section{Keywords}

Internal Control, Xintai Electric Co., Ltd., Financial Fraud

\section{Company Overview of Dandong Xintai Electric Co., Ltd.}

Dandong Xintai Electric Co., Ltd. (Xintai Electric), founded in 1999 and headquartered in Dandong, China, is a subsidiary of Liaoning Xintai Co., Ltd. in China.

Xintai Electric is principally engaged in the research, development, manufac- 
ture and distribution of energy saving electrical transmission and transformation equipment as well as grid performance optimization equipment. Its energy saving electrical transmission and transformation equipment include oil immiscible power transformers, epoxy resin pouring transformers, amorphous alloy iron core transformers, smart box-type substations, smart wind power combined transformers and others. Its grid performance optimization equipment includes magnetically controlled shunt reactors (MCSR), capacitive voltage transformers, high pressure filter capacitors, arc suppression coil single phase and earth fault selection devices, air reactors and others. The company's products are widely applied in the power grid, wind power generation, petrochemical, metallurgy, coal, electric railway, photovoltaic power generation and other areas.

Xintai Electric is sponsored by Industrial Securities Co., Ltd. ("Industrial Securities", Stock Code: 601377.SH). The total amount of proceeds raised from the initial public offering of shares in 2014 is RMB 257,349,112.79. After deducting the issuance expenses, the net proceeds from the Company are RMB $219,999,987.06$.

\section{A Review on Historic Affaires of Xintai Electric in China}

All the time, Xintai Electric Co., Ltd. has attracted attentions from supervision department since its initial public offerings.

On May 31st, 2016, Xintai received an administrative penalty and market access prohibition notification from CSCR, which demonstrated Xintai's financial fraud behaviors meanwhile sending out administrative penalty and market access prohibition to the company and its relevant persons in charge. From then on, Xintai got into trouble of suspending listing. The first signs of financial fraud came up at this point.

As CSCR stated, facts proved that Xintai conducted following illegal acts. Firstly, false financial data records were discovered among its IPO application documents submitted to CSCR. Secondly, there were false records and major omissions in the periodic reports disclosed after listing.

\subsection{Xintai's IPO Application Documents Submitted to CSCR Had False Financial Records}

For the purpose of listing and solving problem of receivable account overbalance, Xintai reduced receivables accounts by external commercial borrowings and repay to strike a balance in the beginning of next period. In two and a half year, from 2011 to June, 2013, Xintai's fictitious collectible accounts added up to 380.58 million yuan, missing bad debt reserve added up to 16.98 million yuan and inflated net cash from operating activities added up to 240.84 million yuan [1] [2] [3].

\subsection{False Accounts Had to Be Covered up by Another False Account}

False records and major omissions lied in Xintai's periodic reports disclosed af- 
ter listing. By external commercial borrowings and forging bank receipts, Xintai continued to reduce receivable accounts and repay to strike a balance in the beginning of next period, which resulted in false financial records in the annual reports of 2013, 2014 and 2015. In reports of 2013 and 2014, Xintai's fictitious collectible accounts added up to 272.02 million yuan, other fictitious collectible accounts added up to 132.18 million yuan, missing bad debt reserve added up to 16.03 million yuan and inflated net cash from operating activities added up to 206.32 million yuan [1] [2] [3].

\subsubsection{Inflate Receivable Accounts}

According to Xintai's audit report, till the end of 2015, receivable accounts for Xintai to collect from Daqing Xintai Co., Ltd. and Daqing Xinheng petroleum equipment Co., Ltd. should be 14.656 and 18.3626 million yuan [4]. Due to contradiction and uncertainty of audit evidences, the auditor couldn't ensure the withdrawal possibility of receivable accounts mentioned above at the end of report. Aiming at such situation, executive of Xintai explained that although Daqing Xintai and Daqing Xinheng had cancelled registration, Xintai was expected to receive the accounts aforementioned, since it had signed a debt transfer protocol with related parties of the two companies. However, as some accountants illustrated to journalist, if the debtor cancelled registration, even though there were other debt undertakers, the company's receivable accounts should also enter bad debts. Entered as receivable accounts, the company may intend to present a false appearance of performance.

\subsubsection{Inflate Other Receivable Accounts}

Besides, Xintai should separately receive another 82.3115 and 41.7994 million yuan for salesman borrowings and nonemployee borrowings. There were no adequate and appropriate audit evidences for the auditor to make reasonable judgments over nature of different payments mentioned above, and the resulting influences on company financial situation and running performance, so as to issue a disclaimer of opinion in the audit report. For this, Xintai admitted that its improper internal control which led to conversion of company funds. The company also checked on related employees and ordered them to return within a definite time.

Table 1 shows that from 2013 to 2015, percentage of Xintai's net receivable accounts occupying total assets reached up to $41 \%, 37 \%$ and $28 \%$, while the proportion occupying current assets went to $52 \%, 46 \%$ and $36 \%$, which constituted the major part of current assets.

Since the end of 2014 till the end of 2015, book balance of Xintai's net receivable accounts annually increased $47.94 \%$, accounting for $71.34 \%$ and $118.79 \%$ in operating revenue. In other words, over seventy percent of sales proceeds haven't been transferred into account as a matter of fact, meaning prime operating revenue depended mainly on receivable accounts, giving rise to irrecoverable debts. 
Table 1. Ratio Comparison of receivable account to current asset and total asset, from 2013 to 2015.

\begin{tabular}{cccc}
\hline item & 2015 & 2014 & 2013 \\
\hline receivable account & 49445.77 & 39004.90 & 20781.95 \\
current asset & 95530.64 & 85509.73 & 57408.24 \\
total asset & 119486.37 & 104339.25 & 75108.83 \\
ratio of receivable account to current asset & 0.52 & 0.46 & 0.36 \\
ratio of receivable account to total asset & 0.41 & 0.37 & 0.28 \\
\hline
\end{tabular}

Source of data: Xintai's annual report from 2013 to 2015.

Among listed company in the same industry, TBEA Shenyang Transformer Company in China was most similar to Xintai in terms of business model. Nevertheless, there was significant difference between the two companies, coming to the following two indicators, receivable accounts turnover rate and total asset turnover rate.

Table 2 shows that Xintai's receivable accounts turnover rate was 0.84 in 2015 while the rate of TBEA was 4.47; Xintai's total asset turnover rate was 0.004 in 2015 while the rate of TBEA was 0.03 . Through studying Table 2, it's worth mentioning that Xintai's receivable accounts turnover rate ranked behind the whole industry at a considerably low level. Such extreme variation shouldn't have been discovered in these indexes, after all, the two companies had much in common as for business mode and main product. Thus Xintai's low receivable accounts turnover rate indicated this listed company may inflate receivable accounts to exaggerate revenues thereby manipulating profits. Great difference came into being when people manipulated data like main business income, net margin or receivable accounts, which turned into Xintai's chief measures for financial fraud.

Table 3 verified the true value of profits. Through data analysis it can be seen that relations between cash flow generated from operations and net profits fluctuated seriously. The cash flow accounted for $340 \%,-344 \%$ and $65 \%$ of net profits apart during these three years. It's large fluctuation range of cash flow in net profits which manifested high possibility of profit fraud.

On August 28th, the company listing Shenzhen GEM on January 27th, 2014 was forced to delist, paying a heavy price for financial fraud during IPO.

So far, Xintai walked through the path of capital market after listing ChiNext for less than four years. It turned out to be the first company delisting from GEM, simultaneously the first to leave delist just because of fraudulent issuing stocks. Xintai's brief history gave a profound lesson that the first company to be forcibly delisted in growth enterprise market for deceitful initial public offering will never appear on the market again.

\section{Internal Controls}

Financial frauds don't come into being overnight; conversely, they are systematic 
Table 2. Comparison of Xintai with TBEA, upon receivable account turnover rate and total asset turnover rate.

\begin{tabular}{ccccc}
\hline \multirow{2}{*}{ item } & \multicolumn{2}{c}{2015} & \multicolumn{2}{c}{2014} \\
\cline { 2 - 5 } & Xintai & TBEA & Xintai & TBEA \\
\hline $\begin{array}{c}\text { receivable account turnover rate } \\
\text { total asset turnover rate }\end{array}$ & 0.84 & 4.47 & 1.40 & 5.42 \\
\hline
\end{tabular}

Source of data: Xintai's and TBEA's annual report from 2013 to 2015.

Table 3. Ratio comparison of net cash flow occurred during business activity to net profit, 2013-2015.

\begin{tabular}{cccc}
\hline item & 2015 & 2014 & 2013 \\
\hline net cash flow occurred during business activity & 1933.23 & -15178.97 & 4095.98 \\
net profit & 567.82 & 4409.98 & 6292.48 \\
Ratio of net cash to net profit & 3.40 & -3.44 & 0.65 \\
\hline
\end{tabular}

Source of data: Xintai's annual report from 2013 to 2015.

activities developing in certain surroundings. Among the reasons for enterprise financial frauds, there are imperfect exterior supervision, absent intermediary organ and most importantly, unhealthy internal control. Driven by profits, legal representatives of Xintai tried every means to beautify their business report by inflating revenues, for the sake of meeting GEM listing conditions or earning higher issuing price. After the initial public offering, with declining performance, they continued to fake financial data in an attempt to relieve the pressure from external supervision, stock price falling and also the investors. Can only benefit motivate such falsehood? The financial fraud case of Xintai exposed more problems other than benefit temptation. What should be of concern is modern enterprise system, unreasonable corporate governance structure, unexecuted internal control, over-concentration of stock right and functioning difficulty of supervisory board.

To find out the underlying causes of financial fraud, we will analyze the internal control of Xintai Electric from the four elements of the internal control framework.

\subsection{Xintai Electric Internal Environment Analysis}

According to the COSO report, the company's internal environment is one of the most basic elements that provides a guarantee for a company's risk management [5] [6]. It sets guidelines for the company's risk management while deciding on a company's structure. At the same time, the company's historical and cultural information will affect the internal environment. From the perspective of the internal environment of Xintai, there are indeed many problems, and the internal environment plays an important role in the entire event of financial fraud. 


\subsubsection{Management Philosophy}

Deyi Wem, Xintai's actual controller, was not only a Xintai's director, but also the chairman and general manager of Liaoning Xintai in China. From the financial fraud incident, the managers treated the accounting statements as a plaything, while tampering with accounting information for personal purposes and seriously violating the quality, reliability, relevance, and cautiousness of accounting information.

\subsubsection{The Integrity and Moral Values}

Xintai operator and accounting supervisor did not adhere to the bottom line of the moral integrity, and the Accounting fraud existed in almost every major production and management sectors, such as supply, storage, production and marketing, and the staffs involved in the fraud were widely distributed in various functions. To achieve the subjective aim, the accounting supervisors made up for the accounting information, and therefore, permeate, honest and trustworthy wiped out in the enterprise. The fake process was like a production line, and each participant had only a corresponding "task". And after the next participant in charge of the next step completed their own task, fake accounts would be logically born in the end.

\subsubsection{Board of Directors}

On the one hand, through the direct shareholder of Liaoning Xintai, Xintai's chairman Deyi Wen and his wife directly or indirectly held a total share of Xintai' shares up to $32.21 \%$ [3]. The second largest shareholder Liaoning Shuguang Industry Co., Ltd. in China, held only $8.16 \%$ share proportion, and it was difficult to form an effective checks and balances of the largest shareholder.

On the other hand, with this highly centralized shareholding structure, the board of directors was emptied and the couple of Deyi Wen actually mastered the corporate control. Although Xintai set up an audit committee whose quality is significantly likely to be associated with the incidence of internal control problems [7], the audit committee under the board of directors controlled by the chairman of the board naturally couldn't play a due supervisory role in the frauds. There were seven members in the board of directors, including three independent directors. Before the fraud exposure, the independent directors did not dispute the basic matters such as the internal control of the company, hired audit firm, annual financial reports and the other basic published issues. And it showed that, the independent directors did not seriously and actually perform their duties and safeguard the legitimate rights and interests of shareholders.

\subsubsection{Human Resources}

Xintai is located in Dandong, Liaoning Province of China. There are abundant and numerous resources there. However, compared to the Yangtze river delta and the pearl river delta region, the economy in Liaoning is relatively less developed. Although Xintai had formed its own talent team after years of development, there was still a lack of high-end management personnel of its human re- 
sources. The existing management team was no longer able to adapt to the constantly expanding enterprise scale, and they also lacked relevant capabilities in financial management, operations and capital markets.

\subsection{Xintai Electric Risk Assessment Analysis}

China faces a very complicated set of challenges as it transitions toward a more open, market oriented economy at present. The economic structure has undergone constant readjustments. The economy growth rate has slowed down. The labor cost has been on the rise. Enterprises are faced with more and more severe operating pressure. Xintai's power transmission system and control equipment manufacturing industry are closely connected with the macroeconomic policies, industrial policies and country's power planning. It's therefore susceptible to the relevant industrial policies.

However, as foreign multinational companies in the power transmission and transformation equipment industries were strengthening their manufacturing and marketing efforts in China, and as well as the domestic enterprises were competing fiercely, there were still a negative impact on the operating performance of Xintai [3]. What's more, instead of introducing professional manager system, Xintai had formed a monopolized decision-making situation that the board of directors and board of supervisors followed blindly under the chairman of the Board of Directors Deyi Wen's leadership. And therefore, in most cases, the staffs couldn't take the initiative to identify and respond the risks during the work.

\subsection{Xintai Electric Control Activities Analysis}

Control activities mainly include five types in practice: business authorization control, responsibility division of labor control, accounting system control, physical control and independent inspection [5] [6].

From the problems Xintai had exposed, it had been seen that there were many deficiencies in the Xintai's control activities, which also gave managers an opportunity to play a trick to inflate revenue. Xintai was lack of independence, and the company and its controlling shareholder were in confusion in the human resources management, the use of printed registration management and so on. And the basis work of accounting was not standardized, including not setting up a separate cash book, inventory cash exceeding the limit and so on. In addition, there were a number of crucial flaws existed in the sales contracts signed with individual customers on the payment time, payment terms and other related provisions. Some significant payments weren't examined and approved. And finally there were loopholes and other specific issues in accounts receivable, other receivables and other related financial management work [4]. In fact, even the most basic cash flow control activities weren't implemented, and the implementation of internal control wasn't promising. However, from another perspective, the implementation of internal control defects may be rooted in its own design 
flaws.

\subsection{Xintai Electric Information and Communication Analysis}

It seemed that Xintai's information system had just been built up and carried out, and the communication between the various functional departments and the management inside the company was not timely, incomplete, and inaccurate. And the information was also seriously asymmetric. According to the survey, the accountants in Xintai responsible for the special fund-raising accounts changed frequently. The staffs did not follow the rules to finish all the handovers, and the accounting executives did not report the problems to the leaders and jointly seek solutions. In the end, only the lack of communication led to the delayed and incomplete fund-raising accounts for a long time.

In terms of external disclosure information, it included the below issues: "Xintai Electric transferred the capital and returned back at the beginning of the next accounting period to made-up accounts receivable from 2011 to 2014, resulting in less provisions for the bad debts of accounts receivable [4]." "Xintai Electric sold four house properties to its related parties. However, it did not submit the issue as a connected transaction to the board of directors and the board of supervisors for deliberation, nor did it disclose the issue in a timely manner in August, 2015 [4]." It didn't fulfill its reporting obligations in time. However, in accordance with the relevant laws and regulations, Xintai promulgated the self-evaluation report on the effectiveness of internal control. And it evaded the important questions for the easy in content and avoided the real problems, forming a huge contrast with the actual situation of its internal control. Therefore, the credibility of the disclosed self-evaluation report needed to be carefully considered.

\section{Measures to Improve Internal Control}

The material weakness revealed from Xintai's case also reflects the serious internal control situation of nowadays domestic listed companies. Internal control not only relates to the running efficiency and development stability of a company, but also directly influences invertors' benefits and sound development of stock market. Against the serious problems of internal control for Xintai and plentiful listed companies, careful attentions need to be paid on COSO risk management framework and corporate governance [8] [9] [10].

\subsection{Optimize Internal Control Environment}

1) Strengthen the awareness of internal control. Before building up an internal control system and making it exert functions well, comprehensive qualities of enterprise managers should be raised.

2) Establish correct moral values among whole staff. Combine honesty and trustworthiness with corporate culture, infiltrate them into every link of enterprise running and realize the conceptual consistency between corporate culture, 
employee value and social moral standard.

3) Enhance functions of executive board. To lay a foundation for scientific and efficient decision-making, there must introduce into modern enterprise system, and separate property right from operation right [8].

4) Improve human resource policy. In order to attract talented person, corporate should broaden the employment channel and fully display self-advantage.

\subsection{Perfect Risk Management System}

Since going public and money-raising project implementing, Xintai step by step got enlarged in capital scale, operation scale and institutional framework, followed by increasing difficulties of operating decision making, organizational administration and risk control. Under such complex circumstances, Xintai should confirm future developing strategies, that is, put emphasis on coping with risk brought by competition in technology market. In terms of perfecting risk management system, it's extremely necessary to equip the whole personnel with risk management awareness, and set up specialized risk management department for dynamic monitoring over major business [9].

\subsection{Improve Internal Control Procedure}

Control activity is concrete measure for enterprise to deal with risk. A serious of control activities constitutes the internal control procedure of a company. They are not restricted to certain hierarchy, department or business, but run throughout business activities of the whole enterprise, more often embodied in business level. Therefore, improve internal control procedure by normalizing control activities, can speed up internal control level of one enterprise.

\subsection{Intensify Information Communication}

The listed company can enhance information communication and exchange through ways like improving communication environment, communication mode and feedback channel. To be specific, a scientific information system includes channels to report information to the superiors, transmit instructions to the subordinates and deliver messages to outside world, by which every participant can fully understand internal information of a company and their own obligations. All these help to create pleasant communication environment.

\subsection{Optimize Corporate Governance}

With productivity development and separating of property right from operation right, modern enterprise system brought forth and expanded, how to safeguard business risk and financial fraud become problems people must settle immediately. Efficient internal control is of great help for reducing operational risk and preventing financial fraud. Whereas, establishment of an efficient internal control system depends not only on various internal control factors, but also sophisticated corporate governance pattern [8] [9] [10]. 


\subsubsection{Found Principal-Agent Relation}

Under the administration structure of ownership and management separating, as modern enterprise system required, Xintai should set up principal-agent relation, properly design inner organizational structure and specify the rights and obligations of staff of all level within enterprise [8]. First, professional managers fit in the corporate are demanded. Second, improve the incentive and constraint mechanism of managers, forming scientific mechanism for policy making, execution and supervision. Manager and stockholders form principal-agent relation, in which a stockholder should entrust a manager to create more wealth with original capitals.

\subsubsection{Reform Ownership Structure}

At present, one serious problem existing in state-owned listed corporate and private company is over-concentration of stock right, which definitely hinders enterprise to move towards scientific administration pattern. In order to regulate operational activities and put forward reasonable policy, corporate can gradually bring in rational investors to disperse stock equity moderately, and further promote the core competence and creativity of corporate [9].

\subsubsection{Enhance Regulation of Independent Director}

Strengthening the regulation of independent directors is built around the premise of maintaining the independence and professionalism of them [10]. Nowadays, most companies in Shanghai and Shenzhen have founded independent director system, yet the system is not playing a due role. The reason for this is that independent directors are actually not independent. In other words, a majority of independent directors are nominated by the largest shareholder, in addition, they usually come from college, universities or research institute that lack connections with enterprises, let alone devote enough time and energy to ponder over business affairs or perform duties.

\subsubsection{Integrate Internal Supervision Resource}

Integrate internal supervision resource, and clearly define each function of audit committee and supervisory board to the greatest extend. At the same time, consolidate the legal authorities of supervisory board, promoting their status in hierarchical structure and have them responsible for shareholders meeting straightway.

\section{Conclusions}

The study on internal control of listed company is based on Xintai Electric in China financial fraud case. On the basis of internal control theory and analysis of its financial fraud case, this article comes up with the improvement measures of internal control from perspective of the COSO risk management framework and corporate governance.

There is a close link between financial fraud and imperfect internal control and corporate governance. The internal control is a fire wall against business 
risk and financial fraud. Any weaknesses in the internal control may lead to internal control failure and even business failure [11]. Besides the corresponding internal control regulations issued by the government, the corporation should design the reasonable and effective internal control to identify and prevent risks and guarantee its healthy and steady development in the increasingly fierce market competition and changeful environment.

\section{References}

[1] Grillo, G. (2013) Xintai Electric Co., Ltd. in China, "Xintai Electric: Annual Reporting 2013". http://data.eastmoney.com/notices/detail/300372/AN201404140005430963,.html

[2] Xintai Electric Co., Ltd. in China, "Xintai Electric: Annual Reporting 2014". http://data.eastmoney.com/notices/detail/300372/AN201504240009360197,.html

[3] Xintai Electric Co., Ltd. in China, "Xintai Electric: Annual Reporting 2015”. http://data.eastmoney.com/notices/detail/300372/AN201604250014529958,.html

[4] Xintai Electric Co., Ltd. in China, "Xintai Electric: Audit Reporting 2015". http://data.eastmoney.com/notices/detail/300372/AN201604250014529965,.html

[5] (1992) The Committee of Sponsoring Organizations of the Treadway Coxnmission, Internal Control Integrated Framework (the COSO Report).

[6] (2004) The Committee of Sponsoring Organizations of the Treadway Commission, Enterprise Risk Management Framework (the COSO Report).

[7] Krishnan, J. (2005) Audit Committee Quality and Internal Control: An Empirical Analysis. Accounting Review, 80, 649-675. https://doi.org/10.2308/accr.2005.80.2.649

[8] Cheng, X.S. (2004) Research of Interactive Relation among Corporate Governance, Internal Control and Organization Structure. Accounting Research, No. 4, 14-18. (In Chinese)

[9] Xie, Z.H. (2007) Internal Control, Corporation Governance and Risk Management: Relationship and Integration. Accounting Research, No. 10, 37-45. (In Chinese)

[10] Yan, D.W. and Yang, Y.H. (2001) Tentative on the Construction of Internal Control Framework. Accounting Research, No. 2, 2-9. (In Chinese)

[11] Doyle, J.T., Ge, W. and McVay, S. (2007) Determinants of Weaknesses in Internal Control over Financial Reporting. Journal of Accounting \& Economics, 44, 193-223. https://doi.org/10.1016/j.jacceco.2006.10.003 